\title{
Quality of life outcomes in patients with breast cancer
}

\author{
Theofilou Paraskevi \\ Panteion University, Department of Psychology, Athens, Greece
}

\begin{abstract}
Health-related quality of life is now considered an important endpoint in cancer clinical trials. It has been shown that assessing quality of life in cancer patients could contribute to improved treatment and could even serve as a prognostic factor along with medical parameters. This paper presents a review of quality of life outcomes in patients with breast cancer according to previous descriptive findings. This is a bibliographic review of the literature covering publications that appeared in English language biomedical journals between 1987 and 2008. The search strategy included a combination of the key words quality of life and breast cancer in the titles of published articles. The major findings are summarized and presented under different headings: evaluation of health-related quality of life i) at the time of diagnosis, ii) during treatment, and iii) after the completion of treatment. Breast cancer patients receiving chemotherapy might experience several side-effects and symptoms that have a negative effect on their quality of life. Also adjuvant hormonal therapies were found to have a similar negative impact on quality of life. Psychological distress-anxiety and depression were found to be common among breast cancer patients. Symptoms-pain, fatigue, and insomnia were among the most common symptoms reported. There was quite an extensive body of literature on quality of life in breast cancer patients. These papers have made a considerable contribution to improving breast cancer care.
\end{abstract}

\section{Introduction}

Breast cancer is the most common cancer among women worldwide. Women are now diagnosed with the disease earlier and live longer. It

Correspondence: Paraskevi Theofilou, Panteion University, Department of Psychology, 12 Eratous, 14568, Athens, Greece.

Tel. $+30.6977 .441502 ;+30.210 .6221435$ - Fax +30.210 .6221435 .

E-mail: theofi@otenet.gr

Key words: quality of life, breast cancer, review, mental health, social function.

Conflicts of interests: the author declares no potential conflicts of interests.

Received for publication: 23 November 2011.

Revision received: 16 January 2012.

Accepted for publication: 16 January 2012.

This work is licensed under a Creative Commons Attribution NonCommercial 3.0 License (CC BY-NC 3.0).

(C)Copyright T. Paraskevi, 2012

Licensee PAGEPress, Italy

Oncology Reviews 2012; 6:e2

doi:10.4081/oncol.2012.e2 is, therefore, crucial to consider the individual woman living with breast cancer and its treatment. ${ }^{1}$ Quality of life has become a wellaccepted outcome measure for cancer patients and an integral part of cancer patient management. ${ }^{2-4}$ This is partly due to the increasing number of breast cancer patients. Statistics show that each year there is over 1.1 million newly diagnosed women with breast cancer worldwide and 410,000 women die from the disease. ${ }^{5}$ On the other hand, improvements in early detection and treatment of breast cancer have led to longer survival of these patients. Also, breast cancer affects women's identities and, therefore, studying quality of life in women who lose their breasts is vital. In addition, women play an important role in family. When a woman develops breast cancer, all family members may develop some sort of illness. ${ }^{6}$

The time of diagnosis, the initial stages of adjuvant treatment and the months immediately following completion of adjuvant treatment are transition times of poor adjustment and decreased quality of life in breast cancer patients. ${ }^{7,8}$ Studies have shown that decreased healthrelated quality of life as a result of chemotherapy side- effects may predict early treatment discontinuation in these patients. ${ }^{9}$ On the other hand, studies on post-treatment adjustment of breast cancer survivors demonstrated that breast cancer patients might benefit from a good quality of life. ${ }^{10}$ However, according to other findings, the end of treatment can be exceedingly stressful for women with breast cancer, especially for those who have received adjuvant chemotherapy and/or radiation treatments. ${ }^{11-15}$

Over the past ten years, much clinical effort has been directed to the treatment of breast cancer in order to improve survival. Now the question is: to what extent have studies of quality of life in breast cancer patients added to our understanding or contributed to improved outcomes in breast cancer care? This is very difficult to answer, but it is possible to try to investigate the contribution of quality of life studies to breast cancer care as a whole. There are several useful papers on quality of life in breast cancer patients. The aim of the present review is to collect and examine publications that have appeared between 1987 and 2008 in English language biomedical journals. It is hoped that this assessment may contribute to existing knowledge, provide both researchers and clinicians with a better profile on the topic, and consequently help improve quality of life in breast cancer patients.

\section{Materials and Methods}

As part of a study on quality of life in breast cancer patients, an extensive literature search was carried out using Medline, Embase, Scopus and PsychInfo database for articles published between 1987 and 2008. We chose 1987 as the earliest year for review to ensure that results would be consistent with current standards of care. To capture literature encompassing a broad set of domains that might be affected by breast cancer or its treatments, we included the following terms in our searches: breast cancer AND quality of life, fatigue, mental health, 
adjustment, social support, OR function. We use the term quality of life to be synonymous with the expression health-related quality of life. We confined our review to original reports of randomized trials and cohort studies. We excluded methodological articles, reviews, case series, and case reports, and non-English language articles.

\section{Results and Discussion}

\section{Quality of life and breast cancer}

Breast cancer is the most common malignancy among women worldwide. Approximately 230,480 new cases of invasive breast cancer and 39,520 deaths are expected among US women in $2011 .{ }^{16}$ Approximately $78 \%$ of new cases and $87 \%$ of breast cancer deaths in 2011 will occur among women aged 50 years and older. In addition to invasive breast cancers, about 57,650 new diagnoses of in situ breast cancer are expected among US women in 2011. ${ }^{16}$

Today, quality of life (QoL) surveys are an important issue in health care, especially in oncological research. Cancer affects different aspects of QoL and currently cancer is a major problem all over the world. The time of diagnosis, the initial stages of treatment and the months following completion of treatment are difficult times for patients both physically and emotionally. During these periods, poor adjustment and decreased QoL in breast cancer patients can easily occur. ${ }^{17,18}$ Therefore, it is critical for health care professionals to become familiar with the impact of a breast cancer diagnosis and its treatment on patients' QoL. ${ }^{19}$

\section{Quality of life among newly diagnosed patients}

Initial diagnosis has been shown to evoke a state of shock, fear and disbelief, thus creating not only a psychological crisis but an existential one as well. ${ }^{20}$ Most women experience at least some psychosocial distress during the course of their breast cancer diagnosis. The level of distress varies from woman to woman and can vary for the individual patient over the course of diagnosis. Cancer-related distress can be expected to dissipate with time for the majority of women diagnosed with cancer. For others, however, such distress may interfere substantially with comfort, QoL and the ability to make appropriate treatment decisions and adhere to treatment. ${ }^{21,22}$ Most of the literature on the psychosocial aspects of breast cancer suggest that the vast majority of women adjust well to the diagnosis of breast cancer, and manage the complex and sometimes aggressive treatments associated with primary treatment and recurrent disease. ${ }^{23-29}$ For a minority of women, however, a diagnosis of breast cancer contributes to significant psychosocial distress that can interfere with functioning and QoL.

\section{Quality of life during the treatment}

\section{Primary treatment}

Once the treatment plan is decided, women with breast cancer may experience some relief of anxiety and distress, but new fears may arise in anticipating and receiving the planned treatment. Surgery, particularly lumpectomy and axillary dissection, is often performed in an outpatient setting or under short stay procedure. Even the length of hospital stay for mastectomy has been shortened from that of just a few years ago. This means that someone must be available to assist the woman at home, particularly with household tasks or other activities that require arm mobility, and provide some nursing care (e.g. management of surgical drains and dressings). Women undergoing mastectomy and immediate reconstruction, especially with soft tissue flaps from the abdomen, will have a longer hospital stay and a more protracted recovery from surgery. A woman needs to be helped to understand what to expect with each of these procedures, and such preparation is important for her psychological well being and recovery. ${ }^{30}$

\section{Adjuvant therapy}

There is a wide range of adjuvant therapies, from tamoxifen as a single agent, to complex chemotherapy regimens with or without tamoxifen, to newer hormonal therapies. It is advisable for a woman to receive as much information and consultation as necessary before embarking on a course of adjuvant treatment. This helps to ensure that she understands which are the most appropriate for her, given her specific medical, personal, and social situation. ${ }^{31-33}$ The process of gathering information is often stressful, but usually leads to a better understanding and acceptance of the treatment plan. ${ }^{34,35}$ Most adjuvant chemotherapy is well tolerated, and women often continue many of their usual activities (childcare, household activities, paid employment), albeit often on a reduced schedule, especially modified by treatment administration. The difficulty here is that the receiver of adjuvant treatment is someone who is trying to recover physically and psychologically from a diagnosis of cancer and surgery, and adds additional associated physical symptoms for a period of from four to six months. While it is perceived by most women as a reasonable insurance policy' gainst subsequent breast cancer recurrence, adjuvant treatment significantly decreases quality of life during the treatment course..$^{34,35}$

After the initial shock of diagnosis and adjustment to treatment, much of the distress is connected to decisions that may impede quality of life and the need to adjust to such physical and emotional changes. Type of surgery, choice of chemotherapy when more than one choice is acceptable, type of radiation therapy (external beam, brachytherapy), and the decision to forgo hormonal suppression are some of the issues that have emotional consequences because they affect anxiety, mood, and stamina. ${ }^{31-33}$

\section{Symptoms}

Symptoms, such as hot flashes on tamoxifen treatment, have been reported to decrease general quality of life in women with breast cancer, either directly or through associated disturbed sleep and fatigue. ${ }^{36}$ Fatigue from treatment, especially in association with pain or other symptoms, can increase anxiety and depression. ${ }^{37}$ In a cross-sectional study of 841 patients, pain, fatigue, and insomnia were significantly related to loss of physical functioning, even after controlling for cancer treatment and comorbid conditions. ${ }^{38}$ In a 1-year follow up of the same cohort, chemotherapy was related to reports of fatigue in the short term but not at 1-year post treatment. ${ }^{39}$

\section{Mental health and overall impact}

The processes of care, including feeling like one had a choice of treatment are also important predictors of health outcomes. For example, in one cohort of female patients, choice was independently associated with reports of better mental health. ${ }^{40}$ Recently, Keating and colleagues extended these results and demonstrated that the concordance between desired and actual decision-making was more important than the actual process itself. ${ }^{41}$ Receiving chemotherapy (yes $v s$. no) has not been related to any long-term mental health outcomes except for having a perception that breast cancer had a greater impact on one's life, even after considering stage and other factors. ${ }^{40}$ One aspect of this negative impact has been distress about the weight gain associated with chemotherapy. ${ }^{42}$

\section{Social and role function}

Social and role functions are inextricably linked to social support and integration prior to breast cancer diagnosis. Breast cancer survivors who are more socially integrated before their diagnosis report better post-treatment role function and vitality than less socially integrated women. ${ }^{43}$ In fact, Michael and colleagues report that social integration 
accounts for greater variance in quality of life than treatment itself. ${ }^{43}$ As a result, others have developed social support interventions targeted to breast cancer survivors with poor support systems. In a recent randomized, prospective trial, the quality of life of older women improved when communicating with a community-based nurse case manager who provided help with managing comorbid conditions, assistance with activities of daily living (ADLs), and help in navigating the health care system. ${ }^{44}$

\section{Caregiver burden}

There is a paucity of data about the impact of breast cancer in older women on their family members and caregivers. Female gender, older age, and past grief experiences have been associated with increased distress and grief in spousal caregivers of cancer patients. ${ }^{45}$ In one study, daughters and sisters of women with breast cancer perceived that their information and support needs were not well met. ${ }^{46}$ In another report, Northouse and colleagues found that family members of patients with recurrent disease experienced decrements in emotional well being, and that negative impact was mediated by the ability of the family to deal with the situation and social support. ${ }^{47}$ Overall, more research is needed to assess caregiver needs and develop appropriate interventions geared to older patients and their families.

\section{Quality of life after the completion of treatment}

At the end of primary breast cancer treatment, whether this is at the conclusion of six weeks of radiation therapy or after 4-6 months of adjuvant chemotherapy, most women experience a mixture of elation, fear, and uncertainty. ${ }^{48}$ Although they have mastered the many aspects of their treatment regimen, they have little preparation and information to guide them in their recovery from treatment. The post-treatment transitional period is a time of considerable psychosocial distress. The paradoxical increase in anxiety has been observed at the end of both radiation and systemic chemotherapy. ${ }^{49}$ Nevertheless, many women find positive meaning and describe posttraumatic growth from the cancer experience. ${ }^{25}$ Nevertheless, fear of recurrence is frequently a dominant emotion that is difficult to control, especially before or during follow-up visits.

There has been growing interest in the late effects of breast cancer treatment and the quality of life of long-term survivors beyond the acute phase of treatment. Several published studies have compared breast cancer survivors to healthy, age-matched populations of women and have found few differences in their long-term physical or emotional well being. ${ }^{50,51} \mathrm{~A}$ recent study of long-term adjustment of women 20 years after treatment in a large multicenter clinical trial found cancer worries to be negligible; however, 18\% of women had posttraumatic stress symptoms, and many reported lymphedema (27\%) and numbness (20\%) as persistent problems. ${ }^{52}$ There is some evidence that women who receive adjuvant therapy may have more physical disruption than those who receive no further therapy, and that women who receive chemotherapy may have more sexual dysfunction, and possibly more cognitive dysfunction, than survivors who did not receive similar therapy. ${ }^{53-57}$ With the growing number of breast cancer survivors, as well as increased research funding targeting this population, new evidence will emerge regarding these cognitive and psychosocial concerns. ${ }^{58}$

\section{Conclusions}

The need for psychosocial intervention amongst cancer patients cannot be understated. The goals of planning a psychosocial intervention in the Greek breast cancer context would be to support the patients' ability to cope with the stress of treatment, helping them to tolerate short-term loss for long-term gain, and to assist in symptom management. ${ }^{59-61}$ However, owing to increased patient burden, in-depth psychological intervention to each patient may not be feasible, and some sort of mechanism to cater for to psychosocial problems needs to be identified. Recognizing the subset of women at risk is one such way forward, followed by targeted intervention, such as patient education and counselling.

\section{References}

1. Ferrell BR, Grant M, Funk B. Quality of life in breast cancer. Physical and social well-being. Cancer Nurs 1997;20:398-408.

2. King CR. Advances in how clinical nurses can evaluate and improve quality of life for Individuals with cancer. Oncol Nurs Forum 2006;33:5-12.

3. Perry SH, Kowalski TL, Chang CH. Quality of life assessment in women with breast cancer: benefits, acceptability and utilization. Health Qual Life Outcomes 2007;5:24-38.

4. Grimison P, Stockler MR. Quality of life and adjuvant systemic therapy for early-stage breast cancer. Expert Rev Anticancer Ther 2007;7:1123-34.

5. Stewart BW, Paul Kleihues P. World Cancer Report. Lyon, France: International Agency Research on Cancer; 2003.

6. Corle DK, Sharbaugh C, Mateski DJ. Self-rated quality of life measures: effect of change to a low-fat, high-fiber, fruit and vegetable enriched diet. Ann Behav Med 2001;23:198-207.

7. Frost MH, Suman VJ, Rummans TA, et al. Physical, psychological and social wellbeing of women with breast cancer: the influence of disease phase. Psychooncology 2000;9:221-31.

8. Schnipper HH. Life after breast cancer. J Clin Oncol 2001;19:3581-4.

9. Richardson LC, Wang W, Hartzema AG, Wagner S. The role of health-related quality of life in early discontinuation of chemotherapy for breast cancer. Breast J 2007;13:581-7.

10. Costanzo ES, Lutgendorf SK, Mattes ML, et al. Adjusting to life after treatment: distress and quality of life following treatment for breast cancer. Br J Cancer 2007;97:1625-31.

11. Ward SE, Viergutz G, Tormey D, et al. Patients' reactions to completion of adjuvant breast cancer therapy. Nurs Res 1992;41:362-66.

12. Fertig DL. Depression in patients with breast cancer: prevalence, diagnosis, and treatment. Breast J 1997;3:292-302.

13. Tross S, Holland JC. Psychological sequelae in cancer survivors. In: JC Holland, JH Rowland (ed.). Handbook of psychooncology: psychological care of the patient with cancer. New York: Oxford University Press;1989. pp. 101-116.

14. Beisecker A, Cook MR, Ashworth J, et al. Side effects of adjuvant chemotherapy: perceptions of node-negative breast cancer patients. Psychooncology 1997;6:85-93.

15. Lethborg CE, Kissane D, Burns WI, Snyder R. "Cast adrift": the experience of completing treatment among women with early stage breast cancer. J Psychosoc Oncol 2000;18:73-90.

16. DeSantis C, Siegel R, Bandi P, Jemal A. Breast Cancer Statistics, 2011. CA Cancer J Clin 2011;61:409-18.

17. Terol MC, Lopez-Roig S, Rodriguez-Marin J. Differences in quality of life: longitudinal study with cancer patients receiving chemotherapy treatment. An Psicol 2000;16:111-22.

18. Redeker NS, Lev EL, Ruggiero J. Insomnia, fatigue, anxiety, depression, and quality of life of cancer patients undergoing chemotherapy. Sch Inq Nurs Pract 2000;14:275-90.

19. Engel J, Kerr J, Schlesinger-Raab A, et al. Predictors of quality of life of breast cancer patients. Acta Oncol 2003;42:710-8.

20. Thomas BC, Pandey M, Ramdas K, Nair MK. Psychological distress 
in cancer patients: Hypothesis of a distress model. Eur J Cancer Prev 2002;11:179-85.

21. Irvine D, Brown B, Crooks D, et al. Psychosocial adjustment in women with breast cancer. Cancer 1991;67:1097-117.

22. Massie MJ, Holland JC. Psychological reactions to breast cancer in the pre- and post-surgical period. Semin Surg Oncol 1991;7:320-5.

23. Bloom JR, Cook M, Flamer DP. Psychological response to mastectomy. Cancer 1987;59:189-96.

24. Ashing-Giwa KT, Padilla G, Tejero J. Understanding the breast cancer experience of women: a qualitative study of African American, Asian American, Latina and Caucasian cancer survivors. Psychooncology 2004;13:408-28.

25. Ganz PA, Coscarelli A, Fred C, et al. Breast cancer survivors: Psychosocial concerns and quality of life. Breast Cancer Res Treat 1996;38:183-99.

26. Ganz PA, Rowland JH, Desmond K, et al. Life after breast cancer: Understanding women's health-related quality of life and sexual functioning. J Clin Oncol 1998;16:501-14.

27. Ganz PA, Desmond KA, Leedham B, et al. Quality of life in longterm, disease-free survivors of breast cancer: A follow-up study. J Natl Cancer Inst 2002;94:39-49.

28. Maunsell E, Brisson J, Deschenes L. Psychological distress after initial treatment of breast cancer. Assessment of potential risk factors. Cancer 1992;70:120-5.

29. Schag CA, Ganz PA, Polinsky ML, et al. Characteristics of women at risk for psychosocial distress in the year after breast cancer. J Clin Oncol 1993;11:783-93.

30. Wickman M. Breast reconstruction: Past achievements, current status, and future goals. Scand J Reconstr Hand Surg 1995;29:81-100.

31. McQuellon RP, Muss HB, Hoffman SL, Russell G. Patient preferences for treatment of metastatic breast cancer: A study of women with early-stage breast cancer. J Clin Oncol 1995;13:858-68.

32. Llewellyn-Thomas HA, Sutherland HJ, Tritchler DL, et al. Benign and malignant breast disease: the relationship between women's health status and health values. Med Decis Making 1991;11:180-8.

33. McNeil BJ, Pauker SG Jr, Sox HC, Tversky A. On the elicitation of preferences for alternative therapies. N Engl J Med 1987;306: $1259-62$.

34. Till JE, Sutherland HJ, Meslin EM. Is there a role for preference assessments in research on quality of life in oncology? Qual Life Res 1992;1:31-40.

35. Yellen SB, Cella DF. Someone to live for: Social well-being, parenthood status, and decision-making in oncology. J Clin Oncol 1995;13:1255-64.

36. Stein KD, Jacobsen PB, Hann DM, et al. Impact of hot flashes on quality of life among postmenopausal women being treated for breast cancer. J Pain Symptom Manage 2000;19:436-45.

37. Stone P, Richards M, A'Hern R, Hardy J. A study to investigate the prevalence, severity and correlates of fatigue among patients with cancer in comparison with a control group of volunteers without cancer. Ann Oncol 2000;11:561-7.

38. Given B, Given C, Azzouz F, Stommel M. Physical functioning of elderly cancer patients prior to diagnosis and following initial treatment. Nurs Res 2001;50:222-32.

39. Given CW, Given B, Azzouz F, et al. Predictors of pain and fatigue in the year following diagnosis among elderly cancer patients. J Pain Symptom Manage 2001;21:456-66.

40. Mandelblatt J, Edge SB, Meropol NJ, et al. Predictors of long-term outcomes in older breast cancer survivors: perceptions versus patterns of care. J Clin Oncol 2003;21:855-63.
41. Keating N, Guadagnoli E, Landrum M, et al. Patients participation in treatment decision making: Should Physicians match patients desired levels of involvement? J Clin Oncol 2002;20:1473-9.

42. McInnes JA, Knobf MT. Weight gain and quality of life in women treated with adjuvant chemotherapy for early-stage breast cancer. Oncol Nurs Forum 2001;28:675-84.

43. Michael YL, Berkman LF, Colditz GA, et al. Social networks and health-related quality of life in breast cancer survivors: a prospective study. J Psychosom Res 2002;52:285-93.

44. Jennings-Sanders A, Anderson ET. Older women with breast cancer perceptions of the effectiveness of nurse case managers. Nursing Outlook 2003;51:108-14.

45. Gilbar 0, Ben-Zur H. Bereavement of spouse caregivers of cancer patients. Am J Orthopsychiatry 2002;72:422-32.

46. Chalmers K, Marles S, Tataryn D, et al. Reports of information and support needs of daughters and sisters of women with breast cancer. Eur J Cancer Care 2003;12:81-90.

47. Northouse LL, Mood D, Kershaw T, et al. Quality of life of women with recurrent breast cancer and their family members. J Clin Oncol 2002;20:4050-64.

48. Rowland JH, Massie MJ. Breast Cancer in Psycho-Oncology. In: J Holland (ed.). New York: Oxford University Press;1989.

49. Holland JC, Rowland JH. Psychological reactions to breast cancer and its treatment. In: JR Harris, S Hellman, IC Henderson, DW Kinne (eds.). Breast Diseases. Philadelphia: Lippincott; 1991. pp. 849-866.

50. Andersen BL, Anderson B, de Prosse C. Controlled prospective longitudinal study of women with cancer. II. Psychological outcomes. J Consult Clin Psychol 1989;57:692-7.

51. Dorval M, Maunsell E, Deschenes L, Brisson J. Type of mastectomy and quality of life for long term breast carcinoma survivors. Cancer 1998;83:2130-8.

52. Kornblith AB, Zhang C, Herndon JE II, et al. Long-term adjustment of survivors of early stage breast cancer 20 years after adjuvant chemotherapy. Cancer 2003;98:679-89.

53. Ahles TA, Saykin AJ, Furstenberg CT, et al. Neuropsychologic impact of standard-dose systemic chemotherapy in long-term survivors of breast cancer and lymphoma. J Clin Oncol 2002;20:485-93.

54. Brezden CB, Phillips KA, Abdolell M, et al. Cognitive function in breast cancer patients receiving adjuvant chemotherapy. J Clin Oncol 2000;18:2695-701.

55. Meyerowitz BE, Desmond KA, Rowland JH, et al. Sexuality following breast cancer. J Sex Marital Ther 1999;25:237-50.

56. Schagen SB, van Dam FS, Muller MJ, et al. Cognitive deficits after postoperative adjuvant chemotherapy for breast carcinoma. Cancer 1999;85:640-50.

57. van Dam FS, Schagen SB, Muller MJ, et al. Impairment of cognitive function in women receiving adjuvant treatment for high-risk breast cancer: High-dose versus standard-dose chemotherapy. J Natl Cancer Inst 1998;90:210-8.

58. Gotay CC, Muraoka MY. Quality of life in long-term survivors of adult-onset cancers. J Natl Cancer Inst 1998;90:656-67.

59. Jacobsen PB, Bovbjerg DH, Schwartz MD, et al. Conditioned emotional distress in women receiving chemotherapy for breast cancer. J Consult Clin Psychol 1995;63:108-14.

60. Shapiro SL, Lopez AM, Schwartz GE. Quality of life and breast cancer: relationship to psychosocial variables. J Clin Psychol 2001; 57:501-19.

61. Payne DK, Sullivan MD, Massie MJ. Women's psychological reactions to breast cancer. Semin Oncol 1996;23:89-97. 